\title{
LOW-DOSE SPINAL ANAESTHESIA FOR HIP FRACTURE SURGERY IN A HIGH RISK PATIENT WITH A CONGENITALLY CORRECTED TRANSPOSITION OF THE GREAT ARTERIES
}

Sabina Štivan, Matej Jenko

Department of Anesthesiology and surgical intensive care, University medical centre Ljubljana, Slovenia

\section{Conclusions}

Hypobaric, low dose spinal anaesthesia can be a method of choice even for patient with multiple comorbid conditions and important heart defect.

\section{Background and Aims}

Hip fracture surgery is a common procedure in patients with multiple comorbidities. We report a case of a 57 years old women receiving home oxygen therapy with congenitally corrected transposition of the great arteries (right ventricle with poor ejection fraction is connected to systemic circulation), situs inversus with dextrocardia, pulmonary hypertension (60 $\mathrm{mmHg}+$ CVP), ventricular septal defect, Wegener granulomatosis and implanted subcutaneous cardioverter/defibrillator who suffered hip fracture during hospitalisation in pulmonology department for treatment respiratory syncytial virus infection and acute respiratory failure.

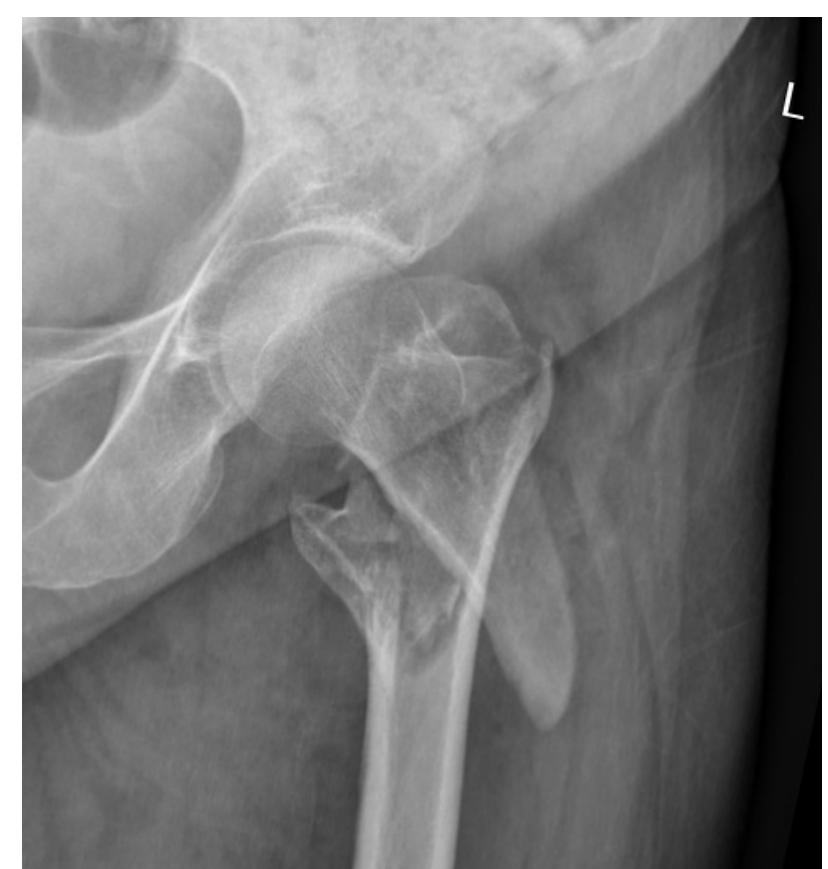

Figure 1: Patient's fractured hip

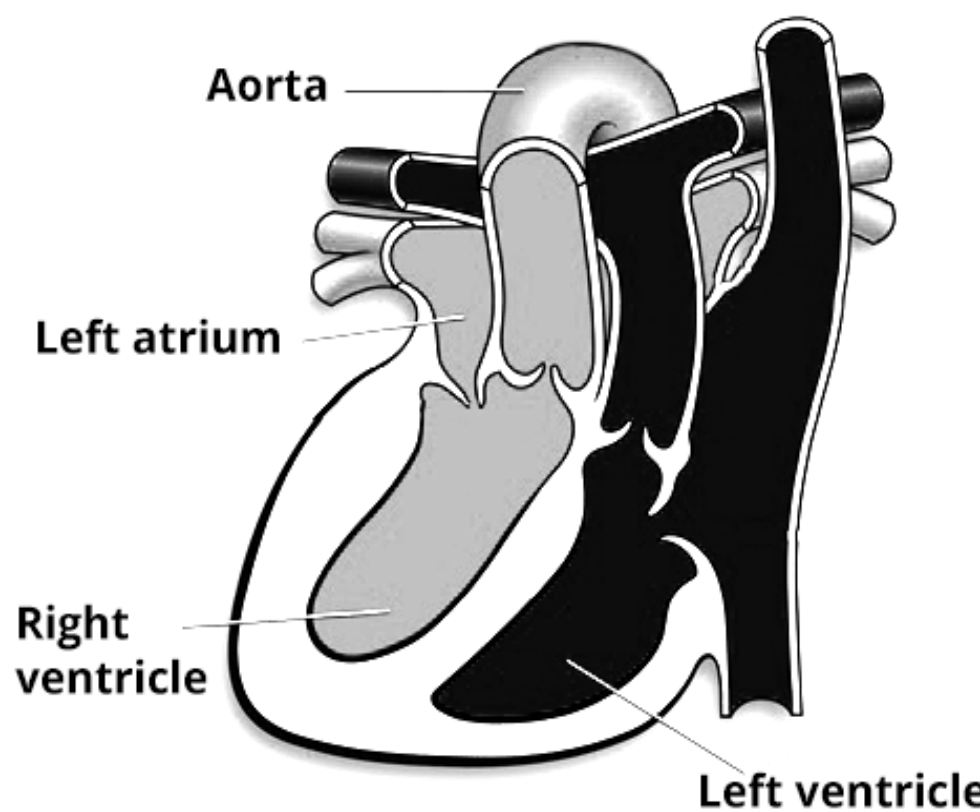

Figure 2: Schematic representation of patient's heart (dextrocardia and congenital corrected transposition of great vessels)

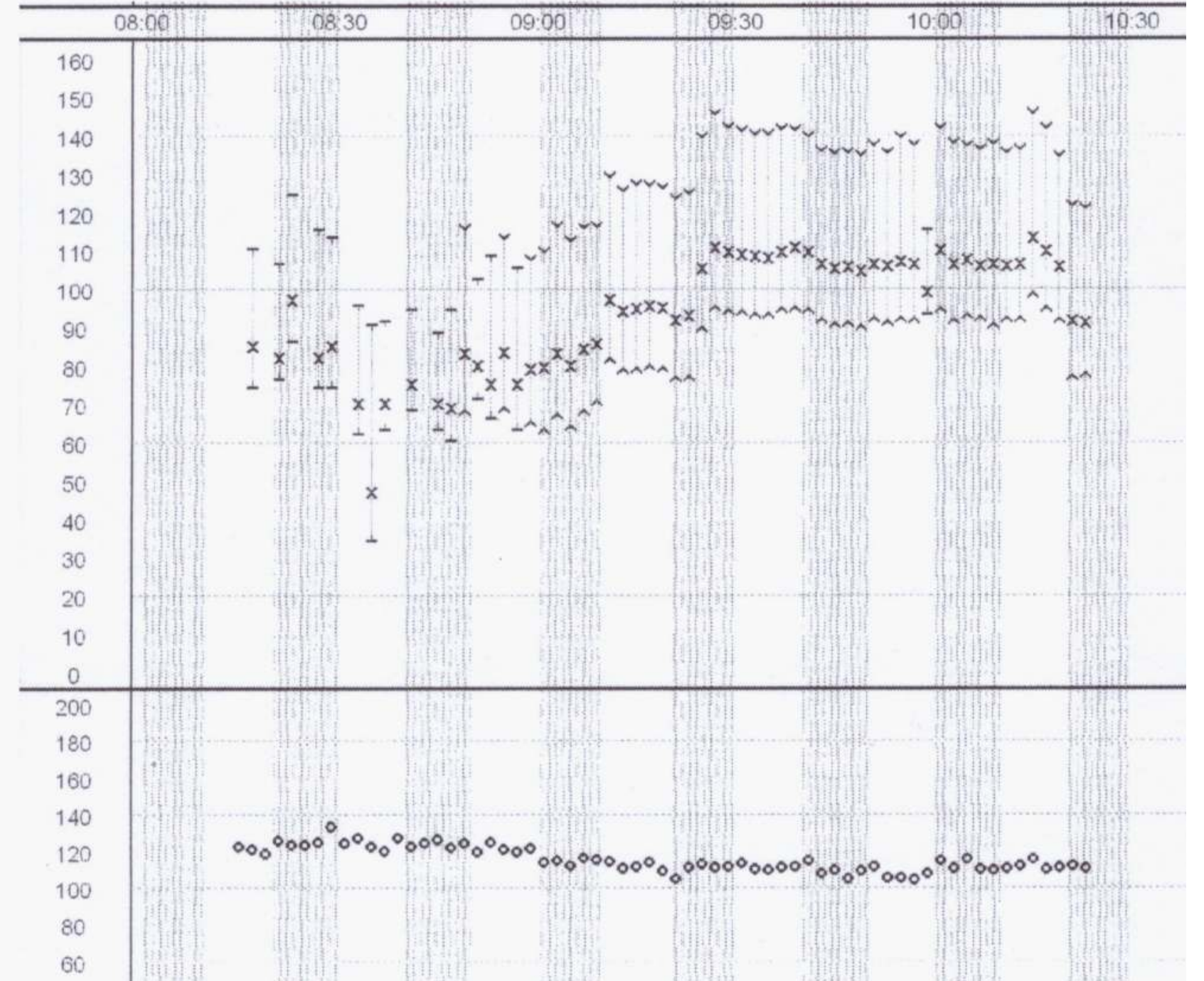

Figure 3: Intraoperative blood pressure profile (in $\mathrm{mmHg}$, upper figure) and heart frequency (beats per minute)

\section{Methods}

The patient was immediately seen by orthopaedic surgeon who reported pertrohanteric fracture 31-A2.3 (AO classification) and has advised proximal femoral nailing antirotation for hip fixation. Patient has reported severe pain (VAS 9-10) and ultrasound guided single shot femoral nerve block was performed (Ropivacaine $0.75 \% 30 \mathrm{ml}$ ). This has resulted in reported VAS 3 - 5 for next 48 hours, after that, surgical procedure was performed.

Arterial line was placed and phenylephrine infusion started. Hypobaric spinal anaesthesia in lumbar 3/4 interspace with $1.5 \mathrm{ml} 0.5 \%$ bupivacaine and $1.5 \mathrm{ml}$ distilled water was conducted. With $500 \mathrm{ml}$ of gelatine and hydrocortisone infusion patient remained normotensive during procedure that lasted 45 minutes.

\section{Results}

She was admitted to HDU after the procedure. The analgesic effect of spinal anesthesia lasted 7 hours. Piritramide infusion and paracetamol were provided afterwards. Acute respiratory failure completely resolved 10 days later and patient was discharged to rehabilitation. By that time, she was able to walk with assistance. No postoperative haemodynamic complications were observed. 